\title{
Age group differences on perception of autoplay in mobile game playing among korean gamers
}

\author{
Doo Heon Song, Seunghun Lee \\ Department of Computer Games, Yong-In SongDam College, South Korea \\ Department of Virtual Reality Contents, Young San University, South Korea
}

\begin{tabular}{|c|c|}
\hline Article Info & ABSTRACT \\
\hline Article history: & \multirow{10}{*}{$\begin{array}{l}\text { Autoplay functions are embedded in most mobile role playing games and } \\
\text { mobile multiplayer online battle arena games recently. Theoretically, there } \\
\text { are different views on autoplay function in that it may be a 'fake play' from } \\
\text { the traditional view and it is economical and gives functional benefits for } \\
\text { game developing companies on balancing from functionalists' view. In this } \\
\text { paper, we investigate how this autoplay functions are perceived to the } \\
\text { Korean mobile gamers. We report that there exists a strong age group effect } \\
\text { on it and age } 25 \text { is the inflection point. Among } 304 \text { subjects including } 69 \\
\text { females participated in this survey, the positive perception rate is positively } \\
\text { proportional to the age from } 36 \% \text { to } 73 \% \text {. The reasons they choose to play } \\
\text { autocombat function are convenience and utilizing sack times but the older } \\
\text { groups (over } 30 \text { ) emphasize playing while doing other personal doings. } \\
\text { Those who do not use autoplay function sustain the traditional view of game } \\
\text { playing in that autoplay is 'not' the real game playing and there exists an age } \\
\text { effect in that the inclination rate of autoplay function is negatively } \\
\text { proportional to the age. }\end{array}$} \\
\hline Received Feb 2, 2020 & \\
\hline Revised Mar 22, 2020 & \\
\hline Accepted Apr 5, 2020 & \\
\hline Keywords: & \\
\hline Age effect & \\
\hline Autoplay & \\
\hline Game play & \\
\hline Mobile game & \\
\hline Survey & \\
\hline
\end{tabular}

Copyright $@ 2020$ Institute of Advanced Engineering and Science. All rights reserved.

\section{Corresponding Author:}

Seunghun Lee,

Department of Virtual Reality Contents,

Young San University,

Busan 48015, Korea Computer Games, South Korea.

Email :shlee@ysu.ac.kr

\section{INTRODUCTION}

In a traditional academic point of view, a computer game or video game is created through the act of gameplay, which is contingent on player acts [1]. It is supposed to require a non-trivial effort from their participants, who in turn need to actively interpret the activity as a game [2] in which players engage in artificial combat, defined by rules, that results in a quantifiable outcome [3]. Thus, games have been described as inherently interactive [4] and often times that interactivity is regarded as a defining characteristic in contrast to non-interactive or less interactive media such as films or books. That is, a game must possess a level of player interactivity that allows the player to have a tangible effect on the progression of the game [5]. Some researchers explicitly emphasize the interactivity in that unless players have some agency to affect the outcome of a game and can intentionally exercise it, they are not really playing a game [6].

In the last decade when mobile platform has been increasingly popular in game market, the autoplay function of the video game has been implemented to mobile games. In tradition, the relationship between a player and the machine (or game software) is that the role of the human is to actively participate in game play, while the role of the machine is to enable, sustain, and facilitate the play [7]. Autoplay is a generic term that allows a program to automatically manipulate a character to obtain items or experience points with no human interaction other than start/stop and it performs repetitive combat without player's direct manipulation [8]. Autoplay function can be activated for both PvE (Player vs Environment) and PvP (Player vs Player) in 
combat situation. Autoplay can be partial automation of the combat in that the player has some level of intervention. When activated by a player, the partial autoplay function can move the character and perform standard attack/defense as designed but the use of a specific skill of the player and ceasing/retrying the combat is done by the player. The full autoplay function, however, needs the player only activate the function after targeting the enemy and all other activity is done by artificial agent. The partial autoplay function is designed for reducing manipulating fatigue in repetitive action whereas the full function is aimed for "watch and get the reward" mode [9].

For mobile role playing games (RPG), which needs the most complex control over objects and feedback of the game, the core mechanics have been ported through casualization to adapt the constraint of the hardware under mobile environment while maintaining the genre-specific experience of growth. Including autoplay function in mobile RPG can decrease the balancing burden of object movement and skill usage that are most difficult to expect in game design since they are entirely under control of player's choice [10]. In result, $80 \%$ of top 5 most downloaded mobile RPG during 2014 and 2016 provide full or partial autoplay functions in combat in Korea [11]. With such adaptation, the fun element of mobile RPG has been transformed into a form that enhances the growth of player character and strategic behavior rather than the immediate interactions caused by detailed manipulation by the player [12]. Even the splendid graphic representation of targeting, movements for attack and defense, and the automatic application of skills make the player to watch the battle scene while autoplay in combat is in progress [13] which is a form of interpassivity [7].

Actually, as the form of software, autoplay function resembles how cheating bot or macro behaves in the game. Thus, the reception of autoplay function is negative at first [9] but there exists some cases that user accepts the function positively in real world [14]. Other study verifies that gamers accept autoplay function because it is convenient to use sack time around lunch time or playing under space constraint like metro commuting situations [15].

Still, the perception of autoplay function in mobile game playing is ambivalent. Different from western world markets, where the combat is considered one of the funniest and appealing aspects of game playing [16], Chinese players like to progress quickly with minimum effort, so when localizing the game for the Chinese market, game companies create a quick-fight system with which players can autoplay the combat scenes [17].

In Korea, there have been a few studies to investigate the reason of using autoplay or perception of the gamers [18-21]. In very recent research, gamers having positive attitude on autoplay function are concentrated on immersion and achievement in the game but gamers feeling fun with manipulation have negative on the function and gamers emphasizing challenges, socializing, and imaginary fun show no preferences [18]. Another study found that gamers felt negatively in lack of interactivity but positively in that they could play a manage-like role in collecting items and growing player character by effectively using autoplay function [19]. Or gamers prefer using autoplay function under their choice in that they want to use it to avoid repetitive action or utilizing sack time but want to participate in only challenging situations [20,21]. However, these previous researches have deficits on their subject populations in survey they performed. In [19], they interviewed 12 games in depth but 10 of them are in age over 30. Similarly, the average age of 11 meaningful subjects in [20] was 38.5 and $61 \%$ of subjects in [21] were in their 30's which is quite higher than average Korean mobile gamers. Thus, unfortunately, the result of these previous researches do not represent demographic standards of Korean gamers especially they do not look at young gamers under age 30 who are the majority of mobile game players [22]. Thus, in this paper, we will focus on young gamers' perception of autoplay function in mobile RPG and mobile Multiplayer online battle arena (MOBA). We try to investigate the perception of autoplay function from teenagers to adult over 30 with meaningful numbers and try to see if there exists any inflection point on perceptions with respect to the age and collect responses on why they prefer/unprefer autoplay functions by a survey.

Recently, there exists an extreme form of autoplaying in games called 'idle game' $[5,7]$ that has almost no interaction in entire game playing. In a recent research with idle games [5], while the existence of interactions in the game are still meaningful to define a game playing even in such idle games, what forms the interactivity - merely watching or actual participation - might be a matter of opinion that differs between players. There were efforts to characterize and taxonomize these idle games on what consist of this extreme type of autoplay games $[23,24]$ and a recent report shows the value of idle game in social exercise games [25]. However, the survey conducted in this paper does not consider idle games as a form of extended autoplay functions and only focused on the usage of autoplay funtion in RPG or MOBA game genre.

\section{ANALYSIS OF AUTOPLAY USAGE BY SURVEY}

The survey is done during May and June of 2017 and the questionnare is with Google docs form thus subjects can answer with ease. Subjects are from many mobile RPG/MOBA game user communities and 
consists of 235 males and 69 females from teens to age over 40. Table 1 summarizes the age group distribution of subjects who represent his/her opinion on the autoplay function usage. Similarily, gender distribution of subjects with his/her autoplay usage is summarized in Table 2.

The response of "not using autoplay" means the subject "currently" not use autoplay in mobile game playing if one has choice. Thus idle game players [5] are not included in this survey. In Table 1, we can find an age cufoff point of age 25 that discriminates the using rate over the age. In Korea, the majority of people age over 25 would have a job and have different daily time schedule from younger groups who would be students in majority. The usage rate of teens is the lowest and virtually a half of age group over 25 thus we can assume that the age is important influencing factor of autoplay functuin usage. Males use autoplay functions more than females but the difference is not overhelming.

Table 1. Autoplay uage by age group

\begin{tabular}{ccccc}
\hline Age Group & Use & Not Use & Total & Rate \\
\hline Teens & 9 & 16 & 25 & $36.0 \%$ \\
$20 \sim 25$ & 101 & 69 & 170 & $59.4 \%$ \\
$26 \sim 30$ & 30 & 12 & 42 & $71.4 \%$ \\
Over 30 & 49 & 18 & 67 & $73.1 \%$ \\
Total & 189 & 115 & 304 & $62.2 \%$ \\
\hline
\end{tabular}

Table 2. Autoplay usage by age group

\begin{tabular}{ccccc}
\hline Gender & Use & Not Use & Total & Rate \\
\hline Male & 152 & 83 & 235 & $64.7 \%$ \\
Female & 37 & 32 & 69 & $53.6 \%$ \\
Total & 189 & 115 & 304 & $62.2 \%$ \\
\hline
\end{tabular}

Among those who play with autocombat function, the dependency of autoplay function is very high in that over $75 \%$ of those subjects say they use the function frequently or over 3 point under 4 point scale Likert choices as shown in Table 3. Overall, the perception of autoplay functtion is high and stable over all age group among those who play with such functions now as shown in Table 4. Only the positive response rate of teens are little lower than other age groups.

Table 3. Dependency of autoplay function

\begin{tabular}{ccc}
\hline Dependency & Users & Rate \\
\hline Greatly & 62 & $32.8 \%$ \\
Much & 80 & $42.3 \%$ \\
Somewhat & 42 & $22.2 \%$ \\
Seldom & 5 & $2.6 \%$ \\
Total & 189 & $100.0 \%$ \\
\hline
\end{tabular}

Table 4. Positive perception of autoplay function among those who play with it

\begin{tabular}{ccccc}
\hline Current User & Positive & Negative & Total & Rate \\
\hline Teens & 6 & 3 & 9 & $66.7 \%$ \\
$20 \sim 25$ & 78 & 23 & 101 & $77.2 \%$ \\
$26 \sim 30$ & 22 & 8 & 30 & $73.3 \%$ \\
Over 30 & 39 & 10 & 49 & $79.6 \%$ \\
Total & 145 & 44 & 189 & $76.7 \%$ \\
\hline
\end{tabular}

In order to investigate the intention of autoplay function and the loyalty to it, we ask the following question for those who currently use autoplay functions.

Question: If the autoplay functions are removed from the game you are playing or if there is no autoplay function in the mobile game you are very interested in, will you still play it?

Surprisingly, the rate of playing intention without autoplay function of the game of interest remarkably decreased in age group 30 or more. A weaker trend of not retaining the game of interest without autoplay function is also found in age group $25 \sim 30$ as shown in Table 5.

Table 5. Intention of using the game without autoplay function among those who play with it

\begin{tabular}{ccccc}
\hline Loyalty & Positive & Negative & Total & Rate \\
\hline Teens & 3 & 6 & 9 & $33.3 \%$ \\
$20 \sim 25$ & 76 & 25 & 101 & $75.2 \%$ \\
$26 \sim 30$ & 20 & 10 & 30 & $66.7 \%$ \\
Over 30 & 21 & 28 & 49 & $42.9 \%$ \\
Total & 120 & 69 & 189 & $63.5 \%$ \\
\hline
\end{tabular}

Age group differences on perception of autoplay in mobile game playing among... (Doo Heon Song) 
We ask for subjects who use autoplay function on what would be the single best reason of their choice and their responses are summarized as shown in Table 6.

Table 6. Reason of using autoplay function among those who play with it

\begin{tabular}{ccc}
\hline Reason & Users & Rate \\
\hline Convenience & 28 & 27.5 \\
Avoid Repetitive Actions & 22 & 21.6 \\
Sack Time Playing & 17 & 16.7 \\
Playing while doing Other thing & 16 & 15.7 \\
Efficient Achievement & 14 & 13.7 \\
Fatigue & 4 & 3.9 \\
Use in the Subway Commuting & 1 & 1.0 \\
Total & 102 & 100.0 \\
\hline
\end{tabular}

As expected and agreeing with previous result [19-21], the main reasons of using autoplay function are 'convenience' or 'avoid repetitive actions'. However, age group over 30 also emplasizes 'sack time playing' and 'playing while doing other things' more than other age groups. That might be the answer of the decrease of playing the game of interest without autoplay function shown in Table 5.

We also ask for subjects who answer 'currently not using autoplay function' on the general perception of the autoplay function as shown in Table 7. Comparing with Table 4 for the same question for those who currently play with it, the positive percepton rate is remarkably low. Thus, they would have specific reason of their choice. We summarize their answer on not using or negative perception of autoplay in Table 8 .

Table 7. Positive perception of autoplay function among those who do NOT play with it

\begin{tabular}{ccccc}
\hline Subjects & Positive & Negative & Total & Positive Rate \\
\hline Teens & 8 & 8 & 16 & $50.0 \%$ \\
$20 \sim 25$ & 19 & 50 & 69 & $27.5 \%$ \\
$26 \sim 30$ & 1 & 11 & 12 & $8.3 \%$ \\
Over 30 & 2 & 16 & 18 & $11.1 \%$ \\
Total & 30 & 85 & 115 & $26.1 \%$ \\
\hline
\end{tabular}

Table 8. Reason of NOT using autoplay function among those who do NOT play with it

\begin{tabular}{ccc}
\hline Reason & Users & Rate \\
\hline Simply Not Interesting & 31 & 39.2 \\
That is not really Gaming & 26 & 32.9 \\
No Participation & 9 & 11.4 \\
No User Superiority of Higher Ranker & 8 & 10.1 \\
No Immersion & 4 & 5.1 \\
No Achievement Feeling & 1 & 1.3 \\
Total & 79 & 100.0 \\
\hline
\end{tabular}

As stated earlier, game playing should involve a tangible effect on the progression of the game from the player $[5,6]$ thus the participation and the interactivity is the joy of game playing from traditional academic definition of game playing. In this survey, people who do not use autoplay even though they have a choice strongly possess this traditional view. Thus, we ask for those who do not choose autoplay function in game playing if they choose autoplay function when the autoplay function is added to the game of their interest.

Question: If the autoplay functions are added to the game you are playing or have interested in, will you play with it?

Comparing with similar question as shown in Table 5, people who choose not playing with autoplay function are consistent in negative position of autoplay perception. As shown in Table 9, high interest of the game does not induce the usage of autoplay or positive perception of it. Another interesting point is that the age effect is also shown in this question in that the inclination rate of autoplay function is negatively proportional to the age. Thus, using autoplay function in mobile game is not favorable for those who sustain the traditional view of game playing and the reason of choosing autoplay function may be depend on the environment of the player (working or not) more than the functionality of the autoplay itself. 
Table 9. Intention of using the autoplay function if added to the game of interest among those who do not play with it

\begin{tabular}{ccccc}
\multicolumn{5}{c}{ play with it } \\
\hline & Positive & Negative & Total & Rate \\
\hline Teens & 7 & 9 & 16 & $43.8 \%$ \\
$20 \sim 25$ & 21 & 48 & 69 & $30.4 \%$ \\
$26 \sim 30$ & 3 & 9 & 12 & $25.0 \%$ \\
Over 30 & 3 & 15 & 18 & $16.7 \%$ \\
Total & 34 & 81 & 115 & $29.6 \%$ \\
\hline
\end{tabular}

\section{CONCLUSION}

In this paper, we analyzed Korean mobile gamers' perception of autoplay function that is prevalent to recent mobile RPG and MOBA games. Theoretically, there exist two extreme positions on game playing in that the traditional view might say unless players have some agency to affect the outcome of a game and can intentionally exercise it, they are not really playing a game meanwhile the radical view would say autoplay function make users enjoying the economy of attention through a gameplay model that does not require constant presence from the players and hence treats their attention as a scarce resource and recurring gratification by means of rewarding the player and elimination of drudgery by automating and/or delegating all the laborious and repetitive in-game activities. In Korea, the most radical form of autoplay called idle game is growing in the market but still far from player's primary choice of game playing. Thus, in this paper, we limit the investigation of the usage of autoplay functions embedded in the combat situation of the game and technically exclude "idle game" genre..

From the survey of 304 gamers over all age groups and 235 males and 69 females participated in this paper, Korean gamers show ambivalent view over autoplay function. Especially, age 25 is the cutoff of how they perceive the autoplay function. The relatively younger groups are reluctant to use the function compared with older groups. However, those who have negative perception on the function are very consistent to their position with very traditional view of game playing while those who accept that function emphasizes the effectiveness of avoiding repetitive action. For those older age group (age over 30), the reason of accepting autoplay function is highly related to use sack time and they can do other things while autoplay proceeds the game with player's minimal intervention. The main contribution of this paper is that using autoplay in mobile games has strong age effect thus autoplay functions should be designed and provided to the target user age group of the game accordingly.

\section{REFERENCES}

[1] Consalvo M. "There is No Magic Circle”, Games and Culture, vol. 4, no. 4, pp. 408-417, 2009.

[2] Aarseth E, Calleja G. "The Word Game: The ontology of an indefinable object". In Proceedings of the 10th International Conference on the Foundations of Digital Games (FDG 2015), Pacific Grove, CA, USA, 2015.

[3] Salen K, Zimmerman E. "Rules of Play-Game Design Fundamentals", Cambridge: MIT Press, 2003.

[4] Ermi L. Mäyrä F. "Fundamental components of the gameplay experience: Analysing immersion". Worlds in play: International perspectives on digital games research, vol. 37, no. 2, pp. 37-53, 2005.

[5] Khaliq I, Purkiss B. "A study of interaction in idle games \& perceptions on the definition of a game". In 2015 IEEE Games Entertainment Media Conference (GEM), pp. 1-6. IEEE, 2015.

[6] Björk S, Juul J. "Zero-Player Games Or: What We Talk about When We Talk about Players", In Proceedings of the 6th Philosophy of Computer Games Conference, Madrid, Spain, 2012.

[7] Fizek, S. "Interpassivity and the joy of delegated play in idle games", Transactions of the Digital Games Research Association, vol. 3, no. 3, pp. 137-163, 2018.

[8] Chen KT, Jiang JW, Huang P, Chu HH, Lei CL, Chen WC. "Identifying MMORPG bots: A traffic analysis approach". EURASIP Journal on Advances in Signal Processing. 2009, Article ID 797159 (online).

[9] Lyou C-G, Kim HH, "Satisfying Desires Using Auto-Combat in Mobile RPG", Journal of Korea Game Society, vol. 15, no. 5, pp. 29-38, 2015.

[10] Rouse III, R. "Game design: Theory and practice”. Jones \& Bartlett Learning, pp. 449-474, 2004.

[11] Lee SH, Song DH, "Functional usability analysis of top korean mobile role playing games based on user interface design", Indonesian Journal of Electrical Engineering and Computer Science (IJEECS), vol. 13, no. 1, pp. 123-128, 2019.

[12] Kim HH, “A study on Playing Pattern of Korean Mobile RPG”, M. A. Thesis, Ewha Women's University, 2017.

[13] Lee J. “A Study on Mobility of Digital Games”, Ph. D. Dissertation, Ewha Women’s University, 2018.

[14] Lyou C-G, Kim HH, "Analysis on Playing Pattern of Mobile RPG's Combat Contents - Focus on 〈Seven Knight〉, Journal of Korea Game Society, vol. 16, no. 5, pp. 69-78, 2016.

[15] Cho E-H. "The Evolution of Smartphone Game System through Auto Play System", Journal of Korea Game Society, vol. 16, mo. 3, pp. 27-34, 2016.

[16] Sinclair B (2016). "How an American company topped China's mobile charts," http://www.gamesindustry.biz/articles/2016-06-02-how-an-american-companytopped-chinas-mobile-charts 
[17] Dong, L., \& Mangiron, C. "Journey to the East: Cultural adaptation of video games for the Chinese market". JoSTRANS. The Journal of Specialised Translation, vol. 29, pp. 149-168, 2018.

[18] Park SE, "Intention of Mobile Game Automatic Combat System-Mediating Effect of Fun Factor", Journal of Arts \& Cultural Management, vol. 12, no. 1, pp. 9-31, 2019.

[19] Lee S-J, Paik C-H, "Type of attitude analysis of the Auto-play mobile games using user", Journal of Korea Game Society, vol. 16, no. 6, pp. 163-172, 2016.

[20] Chang E, "Correlation between Optional Participation and Fun of Automatic Combat System in Mobile Game", M. A. Thesis, Hongik University 2015.

[21] Choi, S. "A Study on the Continuous Usage Intention of Automatic Combat System: Focused on Smart Phone RPG”, M. S. Thesis, Korea University, 2014.

[22] Korea Contents Agency, 2017 Korea Game White Paper, 2017.

[23] Alharthi, S. A., Alsaedi, O., Toups, Z. O., Tanenbaum, J., \& Hammer, J. "Playing to wait: A taxonomy of idle games", In Proceedings of the 2018 CHI Conference on Human Factors in Computing Systems, pp. 1-15, 2018.

[24] Lee, H. "Characterization of Kotrewan Idle games", M. S. Thesis, Aju University, Korea, 2018.

[25] Villareale, J., Gray, R. C., Furqan, A., Fox, T., \& Zhu, J. "Enhancing social exergames through idle game design", In Proceedings of the 14th International Conference on the Foundations of Digital Games pp. 1-5, 2019.

\section{BIBLIOGRAPHY OF AUTHORS}

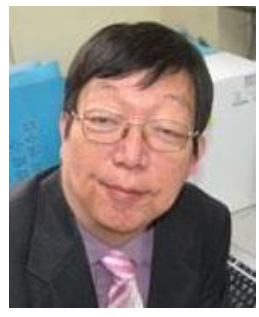

Doo Heon Song received his B.S. degree in Statistics \& Computer Science from Seoul National University, Korea and M.S. degree in Computer Science from the Korea Advanced Institute of Science and Technology in 1983. He received his Ph.D. Candidate Certificate in Computer Science from the University of California at Irvine in 1994. He has been a professor at the Department of Computer Games, SongDam College, Korea, since 1997. He has served as an associate editor for Journal of Multimedia Signal Processing and Information Hiding and The Journal of Information and Communication Convergence Engineering. His research topics include artificial intelligence, medical image processing, machine learning and video game design \& culture.

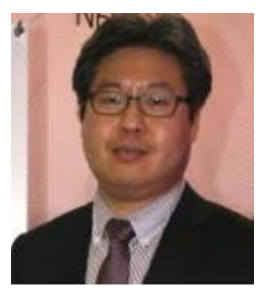

Seunghun Lee received his B.S., M.S., and Ph. D. in Computer Science from Soongsil University, Korea in 2002, 2005, 2012, respectively. He had been the president of Korea Game Developer's Association during 2006-2012. He has been a professor at the Department of Game Contents, Youngsan University, Korea since 2011 and he opens the first ever academic Department of Virtual Reality Contents in Korea since 2017 at the same university. Currently, he leads the VR contents committee in Korea Mobile Game Association and related with many game exhibitions such as G-star. His research interests includes software engineering, software modelling of video game design, snd VR contents design. 